\title{
Reply to Comment on "Spatio-temporal variation of groundwater recharge in response to variability in precipitation, land use and soil in Yanqing Basin, Beijing, China": report published in Hydrogeology Journal (2012) 20:1331-1340, by Huili Gong, Yun Pan and Yongxin Xu
}

\author{
Yun Pan • Huili Gong • Yongxin Xu
}

Keywords Groundwater recharge - Distributed hydrologic modeling $\cdot$ Soil water balance $\cdot$ China

The responding authors appreciate the interest expressed in the Comment regarding the research work described in the subject report (Gong et al. 2012). The Comment mainly focuses on the application of monthly water budget for groundwater recharge estimation in a semiarid environment. The issue of monthly water budget was discussed by Scanlon et al. (2002), cautioning that the accuracy of recharge estimates depends on the other components in the water-budget equation.

The effort to improve accuracy of the monthly water budget in the subject report greatly focuses on the actual evapotranspiration (ET). It is calculated with the FAO (Food and Agriculture Organization) dual crop coefficient approach, which has a good representation of plant transpiration under soil-water deficit, and thus expected a better soil-water-balance simulation. The simulated ET represents a comparable result with the observed pan evaporation, which is often used for ET validation. Moreover, the surface runoff is also validated to guarantee the accuracy of recharge estimates. Although rainfall events are concentrated in wet periods from June to August in the study area, the soil is dry most of the time due to

Received: 31 January 2013 /Accepted: 17 April 2013

Published online: 22 May 2013

(C) Springer-Verlag Berlin Heidelberg 2013

Y. Pan $\cdot$ H. Gong

State Key Laboratory (preliminary) of Urban Environmental Processes and Digital Modeling,

Capital Normal University, Beijing, 100048, China

Y. Pan $(\cdot) \cdot H$. Gong

College of Resources Environment and Tourism,

Capital Normal University, Beijing, 100048, China

e-mail: panyun86@hotmail.com

Tel.: +86-10-68903321

Fax: $+86-10-68903262$

Y. Xu

Department of Earth Sciences,

University of the Western Cape, Bellville, 7535, South Africa evaporative loss. Thus, the missed situation, “...soil field capacity is exceeded...", as asserted in the Comment, may not have a big impact on groundwater recharge. Lastly, the monthly soil-water balance may be a choice for a climatechange-impact study, which usually encompasses a long-term period and uncertainties in daily precipitation projection.

Another issue in the Comment refers to soil parameters used in the subject report. The major soil parameter values are given in Table 2 in the subject report. They are determined mainly with the referenced values according to the soil texture map. The field survey within the wetland reserve confirms expected classification of the soil texture. It has to be noted that soil parameter is one of the big issues that limits the accuracy of distributed hydrological modelling. Although a remote-sensing approach may be a good solution in the future, at present, field sampling and referencing should be the most common choice.

The coefficient $\alpha(0.17)$ derived in the Comment represents a fraction of the precipitation that recharges the aquifer. Although there are no other reported values for the study area, a value of 0.15 can be found in the plain area of Beijing for the year 2005 with a numerical simulation approach (Wang et al. 2010). The value of $77 \mathrm{~mm} / \mathrm{yr}$ derived in the Comment represents a fraction of the precipitation that might be consumed during a recharge process. Since it was derived from the rainfall-recharge relationship, the value will be greatly impacted by the estimated recharge rate. It is lower compared to the general understanding of this area, because the infiltration below the root zone is not available, and thus it may lead to overestimation of recharge, as described in the section "Limitations of the model" in the subject report.

\section{References}

Gong H, Pan Y, Xu Y (2012) Spatio-temporal variation of groundwater recharge in response to variability in precipitation, land use and soil in Yanqing Basin, Beijing, China. Hydrogeol J 20(7):1331-1340

Scanlon BR, Healy RW, Cook PG (2002) Choosing appropriate techniques for quantifying groundwater recharge. Hydrogeol $\mathrm{J}$ 10(1):18-39

Wang L, Liu J, Zhou T, Ye C, Li W, Zhou Y (2010) Analysis of sustainable groundwater resources development scenarios in the Beijing Plain (in Chinese). Hydrogeol Eng Geol 37(1):9-17 